\title{
Incidence and outcomes of perioperative myocardial infarction/injury diagnosed by high-sensitivity cardiac troponin I
}

\author{
Danielle M. Gualandro ${ }^{1,2}$. Christian Puelacher ${ }^{1}$. Giovanna Lurati Buse ${ }^{3} \cdot$ Noemi Glarner $^{1} \cdot$ Francisco A. Cardozo $^{2}$. \\ Ronja Vogt ${ }^{1} \cdot$ Reka Hidvegi $^{1,5}$. Celia Strunz ${ }^{4}$. Daniel Bolliger ${ }^{5}$. Johanna Gueckel ${ }^{1}$ - Pai C. Yu $^{2} \cdot$ Marcel Liffert $^{1,5}$. \\ Ketina Arslani ${ }^{1}$ - Alexandra Prepoudis ${ }^{1}$. Daniela Calderaro ${ }^{2}$. Angelika Hammerer-Lercher ${ }^{6}$. Andreas Lampart ${ }^{5}$. \\ Luzius A. Steiner ${ }^{7,8}$. Stefan Schären ${ }^{9} \cdot$ Christoph Kindler $^{10}$ • Lorenz Guerke ${ }^{11}$. Stefan Osswald ${ }^{1} \cdot$ P. J. Devereaux ${ }^{12}$. \\ Bruno Caramelli ${ }^{2} \cdot$ Christian Mueller $^{1} \cdot$ for the BASEL-PMI Investigators
}

Received: 5 November 2020 / Accepted: 21 February 2021 / Published online: 25 March 2021

(C) The Author(s) 2021

\begin{abstract}
Background Perioperative myocardial infarction/injury (PMI) diagnosed by high-sensitivity troponin (hs-cTn) T is frequent and a prognostically important complication of non-cardiac surgery. We aimed to evaluate the incidence and outcome of PMI diagnosed using hs-cTnI, and compare it to PMI diagnosed using hs-cTnT.

Methods We prospectively included 2455 patients at high cardiovascular risk undergoing 3111 non-cardiac surgeries, for whom hs-cTnI and hs-cTnT concentrations were measured before surgery and on postoperative days 1 and 2 . PMI was defined as a composite of perioperative myocardial infarction $\left(\mathrm{PMI}_{\text {Infarct }}\right)$ and perioperative myocardial injury $\left(\mathrm{PMI}_{\text {Injury }}\right)$, according to the Fourth Universal Definition of Myocardial Infarction. All-cause mortality was the primary endpoint.

Results Using hs-cTnI, the incidence of overall PMI was 9\% (95\% confidence interval [CI] 8-10\%), including PMI Infarct $_{2.6 \%}$ (95\% CI 2.0-3.2) and $\mathrm{PMI}_{\text {Injury }}$ 6.1\% (95\% CI 5.3-6.9\%), which was lower versus using hs-cTnT: overall PMI 15\% (95\% CI 14-16\%), PMI Infarct $_{3.7 \%}$ (95\% CI 3.0-4.4) and PMI Injury $11.3 \%$ (95\% CI 10.2-12.4\%). All-cause mortality occurred in 52 (2\%) patients within 30 days and 217 (9\%) within 1 year. Using hs-cTnI, both $\mathrm{PMI}_{\text {Infarct }}$ and PMI Injury were independent predictors of 30-day all-cause mortality (adjusted hazard ratio [aHR] 2.5 [95\% CI 1.1-6.0], and aHR 2.8 [95\% CI 1.4-5.5],
\end{abstract}

Danielle M. Gualandro and Christian Puelacher have contributed equally to this work.

BASEL-PMI Investigators are listed in the Acknowledgement Section.

Danielle M. Gualandro

danielle.gualandro@usb.ch

1 Department of Cardiology and Cardiovascular Research Institute Basel (CRIB), University Hospital Basel, University of Basel, Spitalstrasse 2, CH-4056 Basel, Switzerland

2 Interdisciplinary Medicine in Cardiology Unit, Cardiology Department, Heart Institute (InCor), University of Sao Paulo Medical School, São Paulo, Brazil

3 Department of Anesthesiology, University Hospital Düsseldorf, Düsseldorf, Germany

4 Laboratory Medicine, Heart Institute (InCor), University of Sao Paulo Medical School, São Paulo, Brazil

5 Department of Anesthesiology, University Hospital Basel, University of Basel, Basel, Switzerland

6 Department of Laboratory Medicine, Cantonal Hospital Aarau, Aarau, Switzerland
7 Department of Laboratory Medicine, University of Basel, Basel, Switzerland

8 Department of Clinical Research, University of Basel, Basel, Switzerland

9 Department of Spinal Surgery, University Hospital Basel, Basel, Switzerland

10 Department of Anesthesiology, Cantonal Hospital Aarau, Aarau, Switzerland

11 Department of Vascular Surgery, University Hospital Basel, University of Basel, Basel, Switzerland

12 Population Health Research Institute, David Braley Cardiac, Vascular and Stroke Research Institute, Anesthesiology, Perioperative Medicine, and Surgical Research Unit C/o Hamilton General Hospital, McMaster University, Hamilton, Canada 
respectively) and, 1-year all-cause mortality (aHR 2.0 [95\% CI 1.2-3.3], and aHR 1.8 [95\% CI 1.2-2.7], respectively). Overall, the prognostic impact of PMI diagnosed by hs-cTnI was comparable to the prognostic impact of PMI using hs-cTnT.

Conclusions Using hs-cTnI, PMI is less common versus using hs-cTnT. Using hs-cTnI, both PMI Infarct $_{\text {and }}$ PMI Injury $_{\text {remain }}$ independent predictors of 30-day and 1-year mortality.

\section{Graphic abstract}

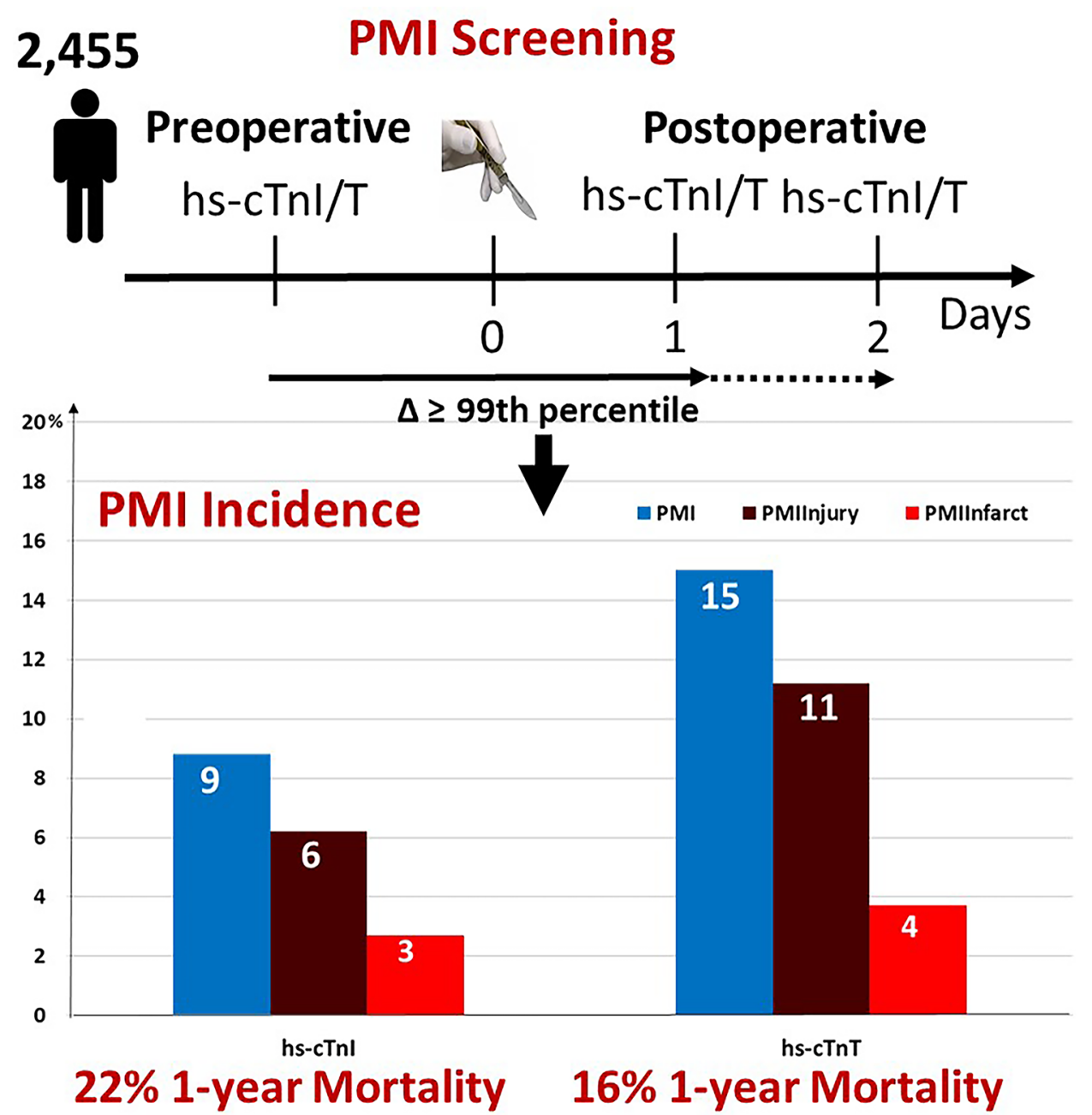

Keywords Myocardial infarction $\cdot$ Myocardial injury $\cdot$ Non-cardiac surgery $\cdot$ High-sensitivity troponin $\cdot$ Perioperative care

\section{Introduction}

More than 300 million surgical interventions are performed annually worldwide [1]. Despite improvements in surgical techniques and anesthesia, the rate of postoperative mortality remains a substantial population problem.[2, 3] Cardiac complications including perioperative myocardial infarction/ injury (PMI) have recently been identified as causal contributors to a substantial number of these deaths [4, 5]. Moreover, PMI portends substantial risk of major cardiovascular events in the subsequent year.
The detection of cardiac complications following noncardiac surgery is challenging for several reasons. [6, 7] Symptoms in this setting are often unspecific or even absent due to analgesia. In addition, clinical signs have low sensitivity, patients are usually not seen by cardiologists, and cardiac imaging and/or cardiac biomarkers are not routinely included in the postoperative care $[4,5,8,9]$. A study implementing routine screening for PMI using preoperative and postoperative measurements of high-sensitivity cardiac troponin (hs-cTn) T found that PMI is asymptomatic in $85 \%$ of patients [4]. The same applies to patients with myocardial 
injury after noncardiac surgery (MINS) considered due to coronary artery disease (CAD). [5, 10, 11] Accordingly, active surveillance is essential for detecting perioperative cardiac complications. [4-7, 12]

While the incidence and outcome of PMI and MINS diagnosed using preoperative and postoperative measurements of hs-cTnT have recently been determined, it is currently unknown whether these findings also apply when using hscTnI. $[4,5,10,11]$ This is of major concern, as cTnI is used more frequently worldwide than cTnT. In addition, evidence for possibly clinically relevant pathophysiological and analytical differences has recently emerged between cTnI and cTnT. For example, cTnT concentrations, but not cTnI, exhibit a diurnal rhythm [13]. In addition, cTnT concentrations have a stronger association with renal dysfunction, which is common in the perioperative setting, than cTnI. $[14,15]$

Therefore, the aim of our study was to evaluate the incidence and outcome of PMI and MINS diagnosed by hs-cTnI, and to directly compare it to PMI and MINS diagnosed with hs-cTnT.

\section{Methods}

\section{Patients}

BASEL-PMI is an ongoing diagnostic study accompanying a systematic PMI screening and response program in highrisk patients with routine measurements of perioperative $\mathrm{cTn}$ concentrations [4]. Briefly, since 2014, consecutive patients undergoing non-cardiac surgery at the University Hospital Basel and the Cantonal Hospital Aarau, both in Switzerland, as well as consecutive patients scheduled for arterial vascular surgery at the Heart Institute, University of Sao Paulo Medical School, Brazil, have been enrolled [4]. The inclusion criteria are age 65-85 years or age above 45 years in the presence of established coronary artery disease, peripheral artery disease or cerebrovascular disease. Patients whose surgery had been cancelled and those who had had cardiac surgery in the two weeks preceding the operation were excluded. For the main analysis, we included consecutive patients in whom at least two measurements of hs-cTnI and hs-cTnT concentrations were available simultaneously. For analyses addressing 30-day and 1-year mortality/major adverse cardiovascular events (MACE), each patient was included only once at first enrollment.

The local ethics committees approved the protocol (NCT02573532/CAPPESQ 610,608), and all patients provided written consent. We adhered to the STROBE guidelines for observational studies (Supplemental eTable 1).

\section{Perioperative assessment}

Before surgery, cardiac risk was classified based on the Revised Cardiac Risk Index (RCRI)[16], and surgical risk was classified as proposed by the European Society of Cardiology and the European Society of Anaesthesiology (ESC/ ESA) [17]. CAD and chronic heart failure at baseline were diagnosed according to previously described criteria. $[4,18]$ Cardiac consultation was performed in patients with PMI detected during routine PMI-screening, a 12-lead ECG was obtained, as well as cardiac imaging as indicated clinically.

\section{Hs-cTnl and hs-cTnT}

Hs-cTnI (ARCHITECT High Sensitive STAT Troponin I assay, Abbott Laboratories, Illinois, USA; 99th percentile upper reference limit (URL) $26 \mathrm{ng} / \mathrm{L}$ ) [19] and hs-cTnT (Elecsys, Roche Diagnostics, Mannheim, Germany; URL $14 \mathrm{ng} / \mathrm{L})[4,5]$ concentrations were measured before surgery and on postoperative days 1 and $2[6,7,12]$.

\section{Definition of PMI, PMI Infarct, $P M I_{\text {Injury' }}$ and MINS}

To comply with the concepts reinforced by the $4^{\text {th }}$ Universal Definition of Myocardial Infarction (UDMI) [12], PMI was defined as a composite of perioperative myocardial infarction $\left(\mathrm{PMI}_{\text {Infarct }}\right)$ and perioperative myocardial injury (PMI Injury $_{\text {. }}$.

$\mathrm{PMI}_{\text {Infarct }}$ was defined as a rise and fall of hs-cTnI/T concentrations, which occurred in the first 3 days after surgery (during the screening period), and which was accompanied by clinical evidence of acute myocardial ischemia demonstrated by one or more of the following: ischemic ECG changes, ischemic symptoms (e.g. chest pain), new regional wall motion abnormalities, or documentation of coronary thrombus [12]. As there is no established delta for the rise and fall in the perioperative period, and to definitely fulfill the request of the UDMI of having at least one value above the URL, an absolute delta of the respective URL of each hs-cTnI/T assay (14 ng/L for hs-cTnT and $26 \mathrm{ng} / \mathrm{L}$ for hs-cTnI) above preoperative concentration (or between two postoperative concentrations if the preoperative value was missing) [4] was used. $\mathrm{PMI}_{\text {Injury }}$ was diagnosed if the hs-cTnI/T delta criteria for $\mathrm{PMI}_{\text {Infarct }}$ were met, but none of the clinical, ECG, and imaging criteria [12, 20].

MINS using hs-cTnT was defined as a postoperative hs-cTnT concentration of 20 to $<65 \mathrm{ng} / \mathrm{L}$ with an absolute change of at least $5 \mathrm{ng} / \mathrm{L}$ or hs-cTnT concentration $\geq 65 \mathrm{ng} / \mathrm{L}$ $[5,10,11]$. All patients with elevations adjudicated to be not due to ischemia such as sepsis, pulmonary embolism, heart trauma, stroke, and atrial fibrillation were not considered to have MINS. We used the same definition for hs-cTnI, except that the range of the hs-cTnI postoperative concentration was 
Table 1 Baseline characteristics of the patients with without PMI, diagnosed by highsensitivity cardiac troponin I (hs-cTnI)

\begin{tabular}{|c|c|c|c|c|}
\hline & $\begin{array}{l}\text { All surgeries } \\
\mathrm{n}=3,111\end{array}$ & $\begin{array}{l}\mathrm{PMI}_{\mathrm{hs}-\mathrm{cTnI}} \\
\mathrm{n}=273\end{array}$ & $\begin{array}{l}\text { No PMI } \\
\mathrm{n}=2,838\end{array}$ & $P$ value \\
\hline Male gender, $n(\%)$ & $1,755(56)$ & $157(58)$ & $1,598(56)$ & 0.749 \\
\hline Age (years), median (IQR) & $73[68-79]$ & $77[70-81]$ & $73[68-78]$ & $<0.001$ \\
\hline Diabetes mellitus, $n(\%)$ & $760(24)$ & $77(28)$ & $683(24)$ & 0.186 \\
\hline No insulin, $n(\%)$ & $492(16)$ & $46(17)$ & $446(16)$ & \\
\hline Insulin, $n(\%)$ & $268(9)$ & $31(11)$ & $237(8)$ & \\
\hline Hypertension, $n(\%)$ & $2,072(67)$ & $207(76)$ & $1,865(66)$ & 0.001 \\
\hline Coronary artery disease, $n(\%)$ & $886(29)$ & $123(45)$ & $763(27)$ & $<0.001$ \\
\hline Peripheral artery disease, $n(\%)$ & $568(18)$ & $94(34)$ & $474(17)$ & $<0.001$ \\
\hline Chronic heart failure, $n(\%)$ & $299(10)$ & $57(21)$ & $242(9)$ & $<0.001$ \\
\hline Atrial fibrillation, $n(\%)$ & $496(16)$ & $61(222)$ & $435(15)$ & 0.003 \\
\hline Stroke/TIA, $n(\%)$ & $309(10)$ & $42(15)$ & $267(9)$ & 0.002 \\
\hline $\mathrm{COPD}^{\mathrm{b}}, n(\%)$ & $456(15)$ & $33(12)$ & $423(15)$ & 0.212 \\
\hline Renal dysfunction ${ }^{\mathrm{a}}, n(\%)$ & $1,473(47)$ & $152(56)$ & $1,321(47)$ & 0.004 \\
\hline Urgent/emergency Surgery, $n(\%)$ & $690(22)$ & $72(26)$ & $618(22)$ & 0.093 \\
\hline \multicolumn{5}{|l|}{ Revised Cardiac Risk Index } \\
\hline I & $1,385(45)$ & $64(23)$ & $1,321(47)$ & $<0.001$ \\
\hline II & $1,046(34)$ & $91(33)$ & $955(34)$ & \\
\hline III & $460(15)$ & $76(28)$ & $384(14)$ & \\
\hline IV & $220(7)$ & $42(15)$ & $178(6)$ & \\
\hline \multicolumn{5}{|l|}{ Preoperative Medications } \\
\hline ASA, $n(\%)$ & $1,014(33)$ & $128(47)$ & $886(31)$ & $<0.001$ \\
\hline Clopidogrel, $n(\%)$ & $90(3)$ & $10(4)$ & $80(3)$ & 0.446 \\
\hline Statins, $n(\%)$ & $1,324(43)$ & $146(53)$ & $1,178(42)$ & $<0.001$ \\
\hline Beta-blockers, $n(\%)$ & $1,164(37)$ & $129(47)$ & $1,035(37)$ & 0.001 \\
\hline $\mathrm{ACEI} / \mathrm{ARB}, n(\%)$ & $1,489(48)$ & $141(52)$ & $1,348(48)$ & 0.205 \\
\hline \multicolumn{5}{|l|}{ Laboratory assessment } \\
\hline Creatinine $^{\mathrm{c}}(\mathrm{mg} / \mathrm{dL})$, median $[\mathrm{IQR}]$ & $0.92[0.75-1.17]$ & $1.04[0.79-1.33]$ & $0.91[0.75-1.15]$ & $<0.001$ \\
\hline $\operatorname{Hemoglobin}^{\mathrm{d}}(\mathrm{g} / \mathrm{dL})$, median [IQR] & $12.8[11.2-14.1]$ & $12.5[10.9-13.9]$ & $12.9[11.3-14.1]$ & 0.074 \\
\hline
\end{tabular}

${ }^{\mathrm{a}}$ Chronic kidney disease stage I-IV, ${ }^{\mathrm{b}} n=3,098^{\mathrm{c}} n=3,066,{ }^{\mathrm{d}} n=3,067$

TIA transient ischemic attack, $C O P D$ chronic obstructive pulmonary disease, $P M I$ perioperative myocardial infarction and injury, $A S A$ aspirin, $A C E I$ angiotensin-converting enzyme inhibitors; ARB angiotensin receptor blockers, $I Q R$ interquartile range considered between 26 and $<65 \mathrm{ng} / \mathrm{L}$ (to comply with the universal definition of having a concentration above the 99th percentile URL of the assay) with an absolute change of at least $5 \mathrm{ng} / \mathrm{L}$ or hs-cTnI concentration $\geq 65 \mathrm{ng} / \mathrm{L}[5,10,11]$.

\section{Clinical endpoints and follow-up}

All-cause mortality was the primary prognostic endpoint. The secondary prognostic endpoint was MACE, defined as a composite of cardiovascular death, acute MI (AMI) after day 3, acute heart failure (AHF) and clinically significant arrhythmias [12]. All-cause mortality and MACE were assessed at 30-days and at 1-year. Detailed definitions are described in Supplemental methods.

Patients were followed by outpatient clinic consultations, by phone, or by contacting their primary care physician.
Additionally, the study investigators requested reports from the general practitioners, treating facilities or death registries. Patients lost to follow-up were censored at last contact.

\section{Statistical analysis}

The incidence of overall PMI and its components (PMI Infarct and $\mathrm{PMI}_{\text {Injury }}$ ) as well as MINS using hs-cTnI and hs-cTnT were calculated with $95 \%$ confidence intervals $(95 \% \mathrm{CI})$. Overall PMI was stratified by surgical disciplines and ESC/ ESA surgical risk. Comparison between baseline characteristics in patients with and without PMI diagnosed by hs$\mathrm{cTnI}$ and hs-cTnT were performed using chi-square test for categorical variables and Kruskal-Wallis test for continuous variables. We calculated the incidence of mortality and 
Table 2 Mortality and MACE within 30 days and 1-year after surgery in patients with or without overall PMI diagnosed by hs-cTnI and hs-cTnT

\begin{tabular}{|c|c|c|c|c|c|}
\hline & $\begin{array}{l}\text { All patients } \\
n=2455 \\
n(\%, 95 \% \text { CI })\end{array}$ & $\begin{array}{l}\mathrm{PMI}_{\mathrm{hs}-\mathrm{cTnI}} \\
n=231 \\
n(\%, 95 \% \mathrm{CI})\end{array}$ & $\begin{array}{l}\text { No PMI }_{\text {hs-cTnI }} \\
n=2224 \\
n(\% ; 95 \% \text { CI })\end{array}$ & $\begin{array}{l}\mathrm{PMI}_{\mathrm{hs-cTnT}} \\
n=330 \\
n(\%, 95 \% \quad \mathrm{CI})\end{array}$ & $\begin{array}{l}\text { No PMI }_{\text {hs-cTnT }} \\
n=2,125 \\
n(\% ; 95 \% \text { CI })\end{array}$ \\
\hline Total mortality 30 days & $52(2 \%, 1.5-3)$ & $20(\mathbf{9 \%}, 5-12)$ & $32(\mathbf{1 \%}, 0.9-2)$ & $24(7 \%, 4-10)$ & $28(\mathbf{1 \%}, 0.8-1.8)$ \\
\hline MACE 30 days & $111(5 \%, 4-5)$ & $38(\mathbf{1 6 \%}, 12-21)$ & $73(3 \%, 2.6-4)$ & $49(\mathbf{1 5 \%}, 11-19)$ & $62(3 \%, 2.2-3.7)$ \\
\hline Cardiovascular death & $24(\mathbf{1 \%}, 0.6-1.4)$ & $14(6 \%, 3-9)$ & $10(\mathbf{0 . 5 \%}, 0.2-0.7)$ & $16(5 \%, 2.5-7)$ & $\begin{array}{c}8(\mathbf{0 . 4 \%} \\
0.1-0.6)\end{array}$ \\
\hline Myocardial infarction & $10(\mathbf{0 . 4 \%}, 0.2-0.7)$ & $2(\mathbf{0 . 9} \%, 0-2)$ & $8(\mathbf{0 . 4 \%}, 0.1-0.6)$ & $5(\mathbf{1 . 5 \%}, 0.2-3)$ & $5(\mathbf{0 . 2} \%, 0-0.5)$ \\
\hline Acute heart failure & $41(2 \%, 1.2-2.2)$ & $17(7 \%, 4-11)$ & $24(\mathbf{1} \%, 0.7-1.5)$ & $18(\mathbf{6 \%}, 3-8)$ & $23(1 \%, 0.7-1.5)$ \\
\hline Arrhythmia & $63(3 \%, 2-3.2)$ & $21(9 \%, 5-13)$ & $42(2 \%, 1.3-2.5)$ & $28(9 \%, 6-12)$ & $35(\mathbf{2 \%}, 1.1-2.2)$ \\
\hline Total mortality 1 year & $217(\mathbf{9 \%}, 8-10)$ & $50(\mathbf{2 2} \%, 17-27)$ & $167(8 \%, 6-9)$ & $59(\mathbf{1 8 \%}, 14-22)$ & $158(7 \%, 6-9)$ \\
\hline MACE 1 year & $212(\mathbf{9 \%}, 8-10)$ & $55(24 \%, 19-30)$ & $157(7 \%, 6-8)$ & $72(\mathbf{2 2} \%, 18-27)$ & $140(7 \%, 6-8)$ \\
\hline Cardiovascular death & $59(2 \%, 1.8-3)$ & $24(\mathbf{1 0} \%, 7-15)$ & $35(2 \%, 1.1-2.2)$ & $25(\mathbf{8} \%, 5-11)$ & $34(\mathbf{2 \%}, 1.1-2.2)$ \\
\hline Myocardial infarction & $39(\mathbf{2 \%}, 1-2.2)$ & $9(4 \%, 2-7)$ & $30(\mathbf{1 \%}, 0.9-2)$ & $14(4 \%, 2-7)$ & $25(1 \%, 0.8-1.7)$ \\
\hline Acute heart failure & $96(4 \%, 3-5)$ & $28(\mathbf{1 2} \%, 9-18)$ & $68(3 \%, 2.4-3.9)$ & $35(\mathbf{1 1 \%}, 8-15)$ & $61(3 \%, 2-4)$ \\
\hline Arrhythmia & $83(3 \%, 2.7-4)$ & $25(11 \%, 7-16)$ & $58(3 \%, 2-3.3)$ & $31(9 \%, 6-13)$ & $52(3 \%, 1.8-3.2)$ \\
\hline
\end{tabular}

$P M I$ perioperative myocardial infarction and injury, MACE major adverse cardiovascular events hs-cTnI high-sensitivity cardiac Troponin I, $h s-$ $c T n T$ high-sensitivity cardiac troponin $\mathrm{T}$

MACE in patients with and without PMI with 95\% CI using Kaplan-Meier estimates.

\section{Association of PMI with the outcomes}

After evaluation of Schoenfeld residuals, we calculated multivariable adjusted hazard ratios (aHR) via Cox proportional hazards models for PMI diagnosed by hs-cTnI and by hs-cTnT for death and MACE. Based on the number of events and the consensus of requiring 10 events for each independent variable, we addressed the following predefined variables: age, RCRI score, urgent/emergency surgery, and postoperative sepsis, pneumonia and stroke [4]. To compare the prognostic impact of PMI diagnosed by hs-cTnI with hscTnT, the statistical significance of the difference between the aHR of PMI $I_{\text {Infarct }}$ and PMI Injury diagnosed by hs-cTnI and hs-cTnT was assessed by bootstrapping. Missing data are indicated in or below the respective tables and figures. No imputation was performed for missing values. We stratified patients according to $\mathrm{PMI}_{\text {Infarct }}$ and $\mathrm{PMI}$ Injury status and constructed Kaplan-Meier plots for 30-day and 1-year mortality and MACE. Curves were compared by the log-rank test. Additionally, we stratified the patients with PMI diagnosed using hs-cTnI in tertiles according to the maximum hs-cTnI delta concentration and constructed Kaplan-Meier plots for 1-year mortality and MACE for comparing the prognosis of patients with delta values in the higher tertile with the ones in the two lower tertiles.

\section{Sensitivity analysis}

As recent studies have suggested that the approved 99th percentile of hs-cTnI $(26 \mathrm{ng} / \mathrm{L})$ may not be biologically equivalent of the 99th percentile of hs-cTnT $(14 \mathrm{ng} / \mathrm{L})$, we performed sensitivity analysis using $8.7 \mathrm{ng} / \mathrm{L}$ (biologically equivalent 99 th percentile) and $16 \mathrm{ng} / \mathrm{L}$ (recently determined to be a reasonable alternative 99th percentile concentration) as the 99th percentile URL and as a delta to diagnose PMI $[21,22]$. Additionally, we performed the same analysis, using $16 \mathrm{ng} / \mathrm{L}$ as an alternative 99th percentile and as a delta to diagnose PMI using hs-cTnT [21]. For these analyes, PMI overall was not stratified into PMIInfarct and PMIInjury because clinical symptoms and ECGs were not systematically done in patients with an hs-cTnI delta lower than $26 \mathrm{ng} / \mathrm{L}$. Finally, we compared the incidence of PMI using hs-cTnT and hs-cTnI with the above-mentioned 99th percentile URL values.

As parallel hs-cTnI and hs-cTnT measurements used for the main analysis were available only in 3,111 cases of the 11,308 patients in our cohort, we performed additional analysis for all patients for whom at least one assay was available. (Supplement eFigure 1).

Statistical analyses were done using SPSS v. 24 and R v.3.6.

\section{Results}

A total of 2,455 patients undergoing 3,111 surgical interventions were eligible for the main analysis (Supplement eFigure 1). Median patient age was 73 years, and $44 \%$ were 

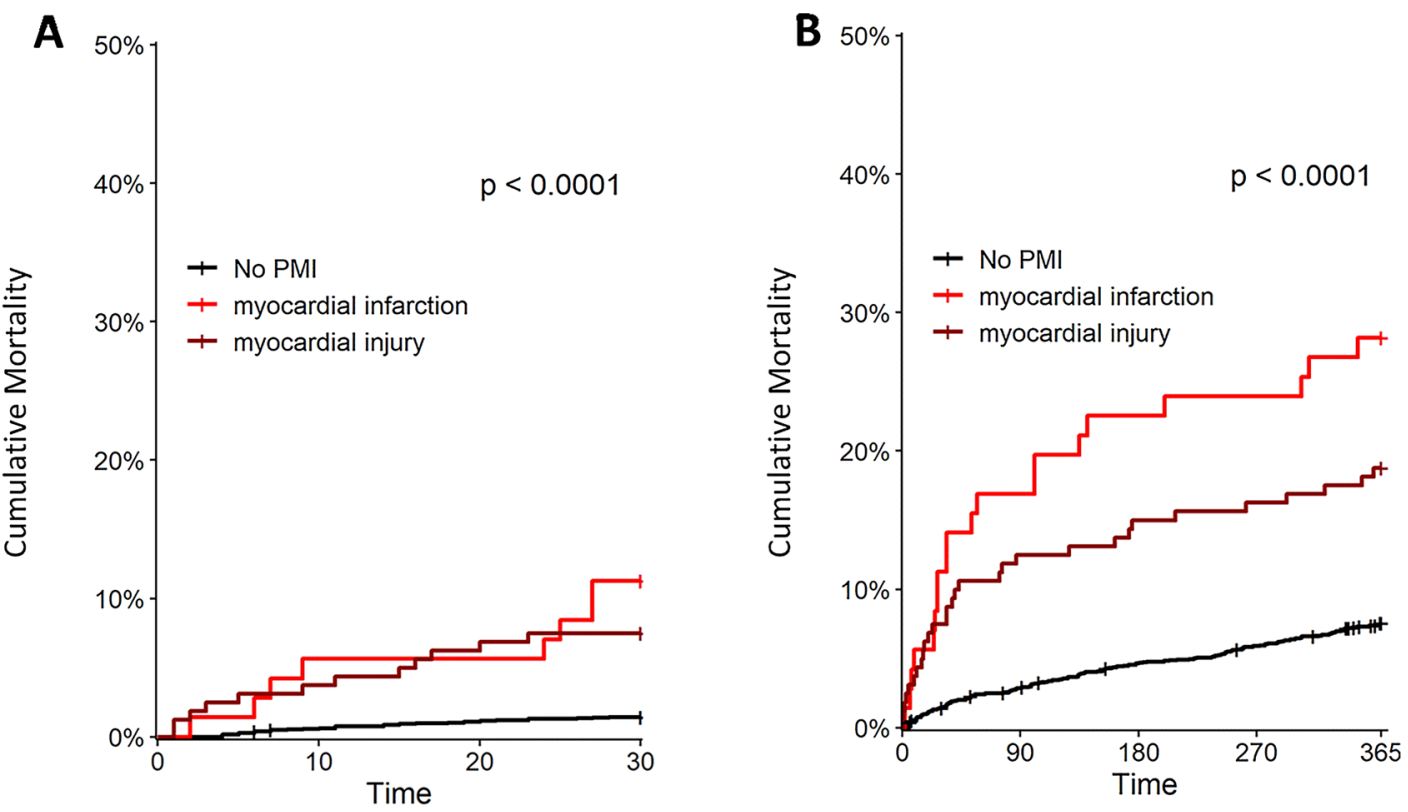

Number at risk

\begin{tabular}{|c|c|c|c|c|c|c|c|c|c|c|}
\hline No PMI & 2220 & 2205 & 2194 & 2186 & No PMI- & 2220 & 2152 & 2109 & 2080 & 2041 \\
\hline myocardial infarction & 71 & 67 & 67 & 63 & myocardial infarction - & 71 & 59 & 55 & 54 & 51 \\
\hline myocardial injury & 160 & 154 & 150 & 148 & myocardial injury - & 160 & 140 & 136 & 134 & 130 \\
\hline & 0 & 10 & 20 & 30 & & 0 & 90 & $\begin{array}{l}180 \\
\text { Time }\end{array}$ & 270 & 360 \\
\hline
\end{tabular}
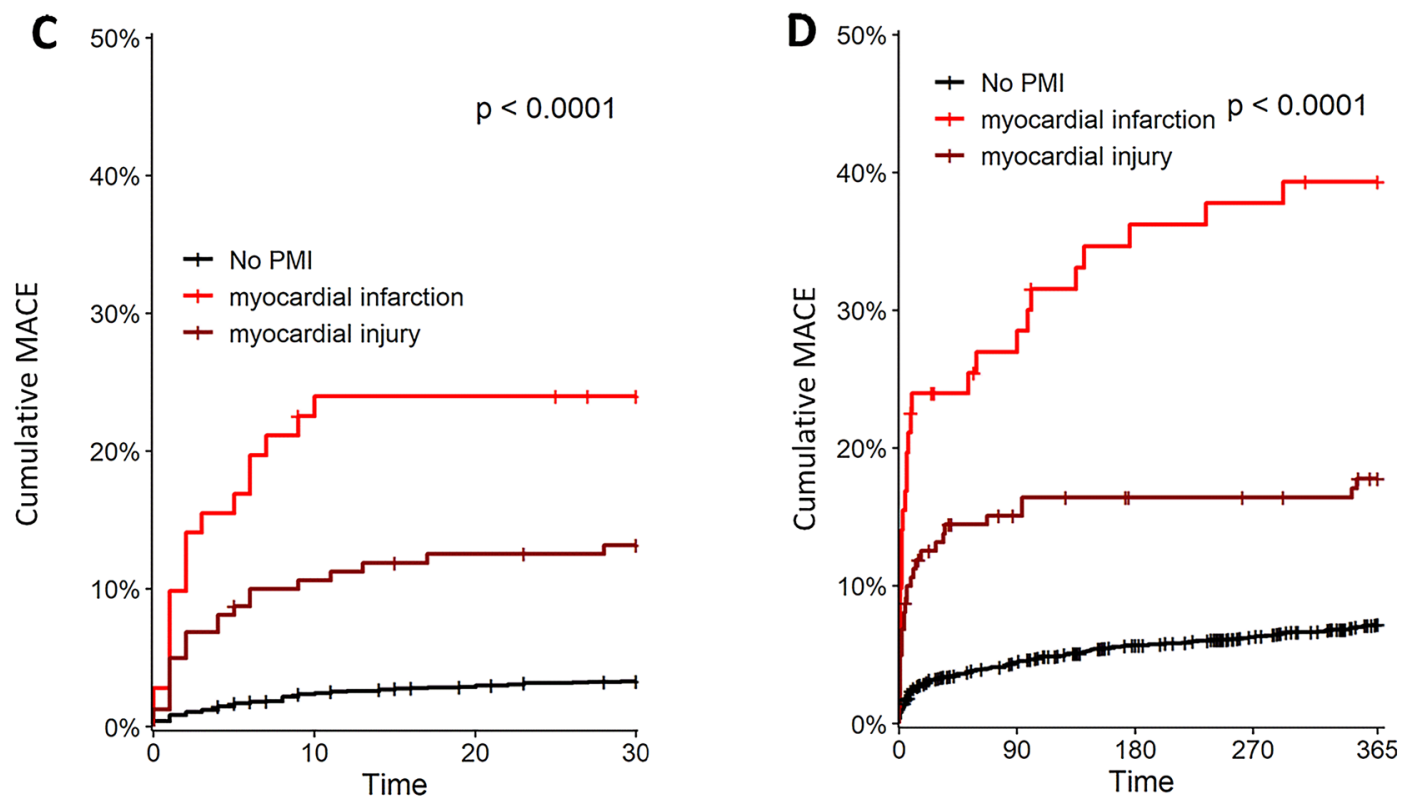

Number at risk

Number at risk

\begin{tabular}{|c|c|c|c|c|c|c|c|c|c|c|}
\hline No PMI & 2216 & 2154 & 2136 & 2124 & No PMI & 2216 & 2080 & 2024 & 1987 & 1939 \\
\hline myocardial infarction & 71 & 54 & 53 & 51 & myocardial infarction & 71 & 48 & 41 & 40 & 38 \\
\hline myocardial injury & 160 & 142 & 138 & 136 & myocardial injury & 160 & 129 & 124 & 123 & 118 \\
\hline & 0 & 10 & 20 & 30 & & 0 & 90 & $\begin{array}{l}180 \\
\text { Time }\end{array}$ & 270 & 360 \\
\hline
\end{tabular}


4Fig. 1 Thirty-day and 1-year mortality after surgery (Panels A and B) and MACE (Panels C and D) in patients with and without PMI diagnosed by hs-cTnI. Hs-cTnI = high-sensitivity cardiac troponin I; $\mathrm{MACE}=$ major adverse cardiac events; $\mathrm{PMI}=$ perioperative myocardial infarction and injury

women (Table 1). Baseline characteristics of patients with and without PMI are shown in Table 1 for hs-cTnI, Supplemental eTable 2 for $\mathrm{PMI}_{\text {Infarct }}$ and $\mathrm{PMI}_{\text {Injury }}$, and Supplemental eTable 3 for hs-cTnT.

\section{PMI and MINS}

PMI diagnosed by hs-cTnI occurred after 273 of the 3111 operations $(8.8 \%$; 95\% CI 8-10\%, Supplement eFigure 2). Considering the PMI individual components, $\mathrm{PMI}_{\text {Infarct }}$ occurred after 82 operations $(2.6 \%$; 95\% CI 2.0-3.2) and $\mathrm{PMI}_{\text {Injury }}$ after 191 operations $(6.1 \%$; 95\% CI 5.3-6.9\%). MINS occurred after 344 operations (11.1\%; 95\% CI 10.0-12.2\%). Seven percent of patients with PMI underwent coronary angiography.

PMI diagnosed by hs-cTnT occurred after 466 of the 3111 operations $\left(15.0 \%\right.$; 95\% CI 14-16\%), $\mathrm{PMI}_{\text {Infarct }}$ after 116 operations $\left(3.7 \%\right.$; 95\% CI 3.0-4.4) and $\mathrm{PMI}_{\text {Injury }}$ after 350 operations $(11.3 \%$; 95\% CI 10.2-12.4\%). MINS occurred after 782 operations $(25.1 \%$; 95\% CI 23.6-26.6). Only $4 \%$ of patients with overall PMI had chest pain, regardless of the assay used for diagnosis, and $87 \%$ had no cardiovascular symptoms. Supplemental eTable $4 \mathrm{a}$ and b shows the surgical characteristics and incidence of overall PMI, diagnosed by hs-cTnI and hs-cTnT, according to the type of surgery and the ESC/ESA risk classification.

\section{Mortality and MACE associated with PMI}

Among 2455 patients eligible for this analysis, follow-up was complete in $99.8 \%$ for mortality and $99.5 \%$ for MACE. All-cause mortality occurred in $52(2 \%)$ patients within 30 days and 217 (9\%) within 1-year (Table 2). Mortality within 30 days and 1 year was significantly higher in patients with PMI versus those without (9\% vs. 1\% [HR 6.2, 95\% CI 4-11] and $22 \%$ vs. $8 \%$ [HR 3.2, 95\% CI 2-4], respectively, for hs-cTnI (Table 2, Fig. 1), $p<0.001 ; 7 \%$ vs. $1 \%$ [HR 5.7, 95\% CI 3-10] and 18\% vs. 7\% [HR 2.6, 95\% CI 2-4], respectively, for hs-cTnT (Table 2, Fig. 2], $p<0.001$ ).

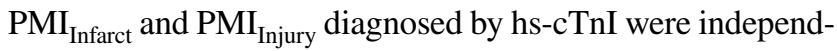
ent predictors of mortality after 30 days and 1 year (Table 3 ), and of comparable prognostic impact versus $\mathrm{PMI}_{\text {Infarct }}$ and $\mathrm{PMI}_{\text {Injury }}$ diagnosed using hs-cTnT ( $p>0.05$; Table 4).

MACE occurred in $111(5 \%)$ patients within 30 days and in $212(9 \%)$ within 1 year (Table 2), and was more prevalent in patients with PMI versus patients without PMI (16\% vs. $3 \%$ [HR 5.4, 95\% CI 4-8] and $24 \%$ vs. $7 \%$ [HR 3.9, 95\% CI
3-5], respectively, for hs-cTnI (Table 2, Fig. 1), $p<0.001$ and $15 \%$ vs. $3 \%$ [HR $5.495 \% \mathrm{CI} 4-8$ ] and $22 \%$ vs. $7 \%$ [HR 3.8, 95\% CI 3-5], respectively, for hs-cTnT (Table 2, Fig. 2), $p<0.001)$. Additionally, $\mathrm{PMI}_{\text {Infarct }}$ and $\mathrm{PMI}_{\text {Injury }}$ diagnosed by hs-cTnI, as well as diagnosed by hs-cTnT were also independent predictors of MACE within 30 days and 1 year (Tables 3, 4). Overall, the prognostic impact of $\mathrm{PMI}_{\text {Infarct }}$ and $\mathrm{PMI}_{\text {Injury }}$ for MACE diagnosed by hs-cTnI was comparable to PMI using hs-cTnT $(p>0.1)$.

Patients with PMI and a hs-cTnI delta value in the highest tertile had worse prognosis than PMI patients with lower hscTnI delta concentrations (Supplemental eFigure 4).

\section{Sensitivity analysis}

Sensitivity analysis using hs-cTnI cut-off values of $8.7 \mathrm{ng} / \mathrm{L}$ and $16 \mathrm{ng} / \mathrm{L}$ for the diagnosis of PMI showed an incidence of $15.7 \%$ (14-17\%) and $11.6 \%$ (95\% CI 11-13\%), respectively. Using a cut-off of $16 \mathrm{ng} / \mathrm{L}$, mortality within 30-days and 1-year was significantly higher in patients with PMI versus those without ( $8 \%$ vs. $1 \%$ [HR 6.3, 95\% CI 4-11] and $20 \%$ vs. $7 \%$ [HR 2.9, 95\% CI 2-4], respectively). MACE rates in 30-days and 1-year were also higher in patients with PMI (15\% vs. 3\% [HR 5.0, 95\% CI 3-7] and 23\% vs. $7 \%$ [HR 3.8, 95\% CI 3-5], respectively). In the multivariable analysis, PMI diagnosed by a delta of $16 \mathrm{ng} / \mathrm{L}$ was also an independent predictor for death within 30 days and 1 year (aHR 3.0 [95\% CI 1.7-5.4; $p<0.001]$ and aHR 1.8 [95\% CI 1.3-2.5; $p<0.001]$, respectively) and MACE (aHR 2.5 [95\% CI 1.7-3.9; $p<0.001]$ and aHR 2.2 [95\% CI 1.6-3.1; $p<0.001]$, respectively). Regarding hs-cTnT, sensitivity analysis using a delta hs-cTnT value of $16 \mathrm{ng} / \mathrm{L}$ for the diagnosis of PMI showed an incidence of $12.1 \%$ (95\% CI 11-13\%). In the multivariable analysis, PMI diagnosed by hs-cTnT using a delta of $16 \mathrm{ng} / \mathrm{L}$ was also an independent predictor for death within 30 days and 1 year (aHR 2.6 [95\% CI 1.4-4.7; $p=0.001]$ and aHR 1.8 [95\% CI 1.3-2.4; $p=0.001]$, respectively) and MACE (aHR 2.0 [95\% CI $1.3-3.1 ; p=0.002]$ and aHR 2.0 [95\% CI 1.4-2.7; $p<0.001]$, respectively).

The incidence of PMI diagnosed by several 99th percentile URL is shown in Supplement eTable 5.

Sensitivity analysis for the association between PMI and mortality/MACE in all patients for whom each assay was available (4,842 cases for hs-cTnI and 8,659 for hs-cTnT) is shown in Supplemental results. MINS diagnosed by hs-cTnI was an independent predictor for MACE and mortality after 30 days and 1 year (Supplemental eTable 8, Supplemental eFigure 3). 

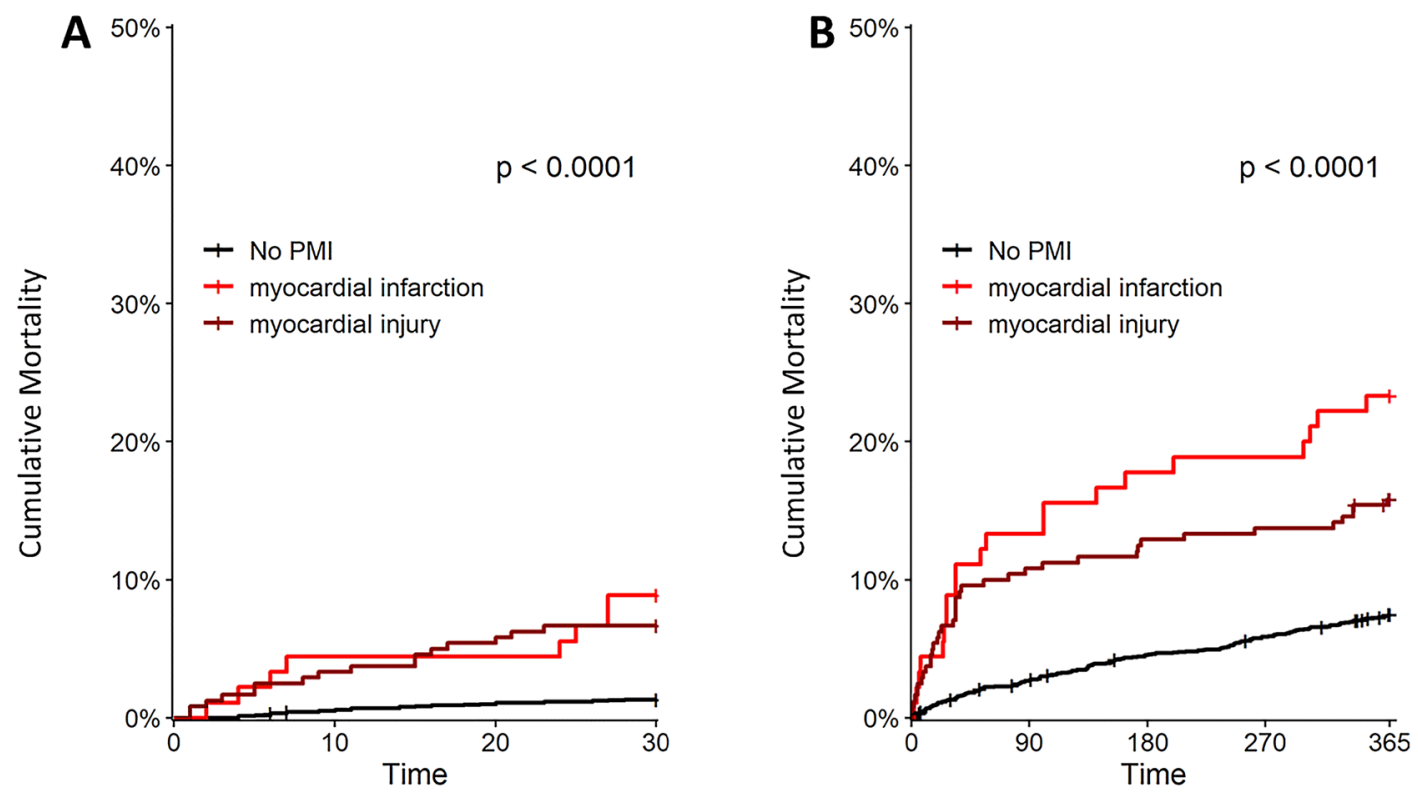

\section{Number at risk}

\begin{tabular}{|c|c|c|c|c|}
\hline No PMI & 2121 & 2108 & 2098 & 2091 \\
\hline myocardial infarction & 90 & 86 & 86 & 82 \\
\hline myocardial injury & 240 & 232 & 227 & 224 \\
\hline & 0 & 10 & 20 & 30 \\
\hline
\end{tabular}

Number at risk

\begin{tabular}{|c|c|c|c|c|c|}
\hline No PMI & 2121 & 2059 & 2017 & 1988 & 1951 \\
\hline hyocardial infarction & 90 & 78 & 74 & 73 & 69 \\
\hline myocardial injury & 240 & 214 & 209 & 207 & 202 \\
\hline & 0 & 90 & $\begin{array}{l}180 \\
\text { Time }\end{array}$ & 270 & 360 \\
\hline
\end{tabular}

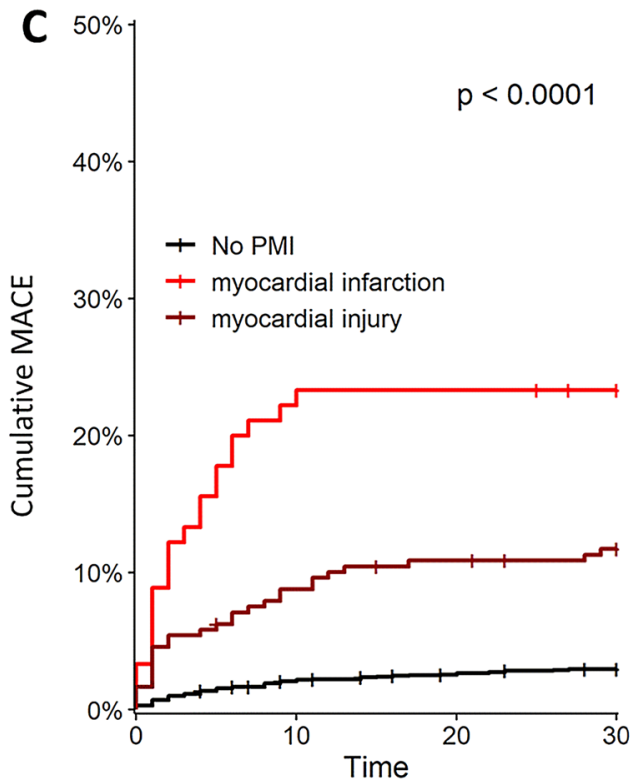

Number at risk

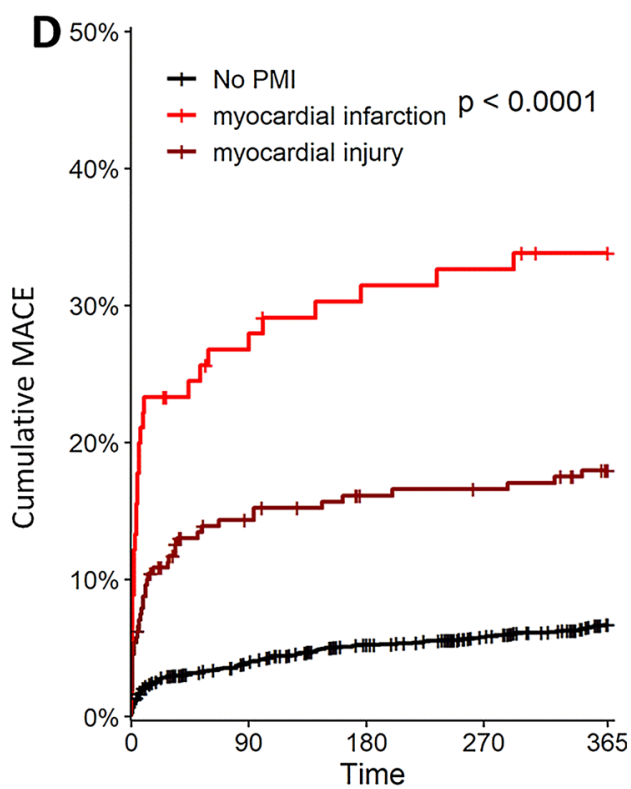

Number at risk

No PMI-2117 $2001 \quad 1947 \quad 1911 \quad 1865$

No PMI $-2117 \quad 2063 \quad 2048$ myocardial infarction -90

myocardial injury 24
6 myocardial infarction \begin{tabular}{ccccc}
-90 & 63 & 58 & 57 & 54 \\
240 & 193 & 184 & 182 & 176 \\
\hline 0 & 90 & 180 & 270 & 360
\end{tabular} 
4Fig. 2 Thirty-day and 1-year mortality after surgery (Panels A and B) and MACE (Panels C and D) in patients with and without PMI diagnosed by hs-cTnT. Hs-cTnT = high-sensitivity cardiac troponin T; $\mathrm{MACE}=$ major adverse cardiac events; $\mathrm{PMI}=$ perioperative myocardial infarction and injury

\section{Discussion}

This prospective diagnostic multicenter study evaluated the incidence and outcome of PMI and MINS after non-cardiac surgery diagnosed by hs-cTnI, the most widely used biomarker of cardiomyocyte injury, and compared it to PMI and MINS diagnosed by hs-cTnT. Important pathophysiological and analytical differences between cTnI and cTnT mandated this analysis to complement recent studies using hs-cTnT [4, $5,23]$. We report four major findings.

First, using hs-cTnI 9\% of patients developed PMI following non-cardiac surgery. Thus, the incidence of PMI using hs-cTnI was considerably lower compared to that using hscTnT $(15 \%)[4,5]$. This finding was confirmed when analyzing MINS, as well as in sensitivity analysis with an even larger sample of patients, for whom each assay was available (PMI in 9\% for hs-cTnI versus 16\% for hs-cTnT). This difference persisted in part in sensitivity analyses using a recently suggested lower 99 th percentile for hs-cTnI ( $16 \mathrm{ng} / \mathrm{L})$ compared to that of hs-cTnT using the manufacturer $99^{\text {th }}$ percentile of $14 \mathrm{ng} / \mathrm{L}$ ( $11.6 \%$ for hs-cTnI and $15 \%$ for hs-cTnT) [21]. However, after comparison of this lower hs-cTnI $99^{\text {th }}$ percentile with an alternative 99th percentile for hs-cTnT of $16 \mathrm{ng} / \mathrm{L}$, the difference did not persist (PMI in $11.6 \%$ for hs-cTnI and $12.1 \%$ for hs-cTnT). Additionally, by lowering the hs-cTnI $99^{\text {th }}$ percentile to $8.7 \mathrm{ng} / \mathrm{L}$, there was also no difference as compared to the hs-cTnT manufacturer's 99th percentile of $14 \mathrm{ng} / \mathrm{L}$ (PMI incidence of $15.7 \%$ for hs-cTnI and $15 \%$ for hs-cTnT). Therefore, non-biological equivalence of the approved URL of each assay may have contributed to the lower incidence observed with hs-cTnI, but a different release pattern after perioperative triggers might contribute as well. [13, 14, 24-29] Second, as described previously for PMI and MINS diagnosed with hs-cTnT, the vast majority of PMI and MINS diagnosed with hs-cTnI was asymptomatic and would have been missed without systematic screening $[4,5,9-11,23]$. Third, the 30-day and 1-year mortality of patients developing PMI, PMI Infarct $_{\text {and PMI }}$ Injury was much higher, than those of patients without PMI, regardless of the hs-cTn assay used. Similarly, the 30-day and 1-year rate of developing MACE including spontaneous AMI, AHF, clinically relevant arrhythmias and cardiac death was fivefold and threefold higher, respectively, in patients with PMI, compared to patients without PMI, regardless of the hs-cTn assay used. All these associations persisted after multivariate adjustments. Therefore, the findings of this study provide further support to the current recommendation of the
European Society of Cardiology, the American Heart Association, and the American College of Cardiology to screen high-risk patients on a regular basis [12]. There is no evidence supporting a preference for one of both hs-cTn assays for such routine screening. We also confirmed that MINS diagnosed by hs-cTnI has important prognostic significance [30-34]. Fourth, in patients with PMI, there was no difference in short- or long-term mortality between the subgroups of patients classified as $\mathrm{PMI}_{\text {Infarct }}$ and $\mathrm{PMI}_{\text {Injury }}$. This confirms prior findings with $\mathrm{PMI}_{\text {Infarct }}$ and $\mathrm{PMI}_{\text {Injury }}$ diagnosed using hs-cTnT. In contrast, the risk of developing MACE was further increased in patients classified as $\mathrm{PMI}_{\text {Infarct }}$. This possibly suggests that if additional criteria requested by the 4th UDMI including ischemic symptoms, ECG changes, or wall motion abnormalities are present, extensive cardiac workup including non-invasive and/or invasive coronary angiography may have the highest yield in the attempt to decrease MACE rates [9].

These findings extend and corroborate previous findings regarding PMI and MINS using hs-cTnT as important contributors to perioperative morbidity and mortality [4, 5, 23]. The substantially lower incidence of PMI and MINS using hs-cTnI as compared to hs-cTnT contributes to an increasing number of clinical differences emerging between both quantitative markers of cardiomyocyte injury [13-15, 27, 29]. The predominate triggers and the exact pathophysiological mechanisms underlying release of cTnT/I from cardiomyocytes in the perioperative setting are largely unknown and a matter of ongoing research $[25,26]$.

These findings are specific for the most widely validated hs-cTnI assay. Future studies are required to document the prevalence and prognostic impact of PMI and MINS diagnosed with other hs-cTnI, as well as less sensitive cTnI and cTnT assays.

The most appropriate early management measures in patients detected to have PMI are only slowly evolving. Based on detailed clinical assessment including the intraoperative course combined with the 12-lead ECG and basic laboratory values including hemoglobin the most likely cause of PMI needs to be evaluated (Fig. 3). The most common etiologies include type 2 myocardial infarction, type 1 myocardial infarction, acute heart failure and tachyarrhythmia [35]. As PMI-screening by design always also provides a hs-cTnI/T concentration prior to surgery (to differentiate acute from chronic cardiomyocyte injury), and previous pilot studies had shown moderate to high prognostic accuracy of preoperative hs-cTnI/T concentration for 30-day mortality, preoperative hs-cTnI/T concentration may improve risk prediction and help physicians and patients in assessing the risk-benefit ratio of the planned surgery $[18,36]$.

This study has several limitations. First, screening was performed only in patients at increased cardiovascular risk. We cannot comment on the incidence and outcome of PMI 
Table 3 Multivariable Cox regression models for the prediction of MACE and mortality within 30 days and 1 year after surgery (PMI diagnosed by hs-cTnI)

Table 4 Multivariable Cox regression models for the prediction of MACE and mortality within 30 days and 1-year after surgery (PMI diagnosed by hs-cTnT)

\begin{tabular}{|c|c|c|c|c|}
\hline & $\begin{array}{l}\text { Adjusted hazard } \\
\text { ratio }(95 \% \mathrm{CI}) \\
30 \text { days }\end{array}$ & $P$ value & $\begin{array}{l}\text { Adjusted hazard } \\
\text { ratio }(95 \% \mathrm{CI}) \\
1 \text { year }\end{array}$ & $P$ value \\
\hline \multicolumn{5}{|l|}{ Mortality } \\
\hline Age, per year & $1.03(0.99-1.07)$ & 0.103 & $1.05(1.02-1.07)$ & $<0.001$ \\
\hline \multicolumn{5}{|l|}{ PMI } \\
\hline $\mathrm{PMI}_{\text {Infarct }}$ & $2.50(1.05-5.96)$ & 0.039 & $2.02(1.23-3.31)$ & 0.006 \\
\hline $\mathrm{PMI}_{\text {Injury }}$ & $2.79(1.40-5.55)$ & 0.004 & $1.79(1.20-2.68)$ & 0.004 \\
\hline RCRI Score $\geq$ II & $3.73(2.10-6.61)$ & $<0.001$ & $2.17(1.63-2.89)$ & $<0.001$ \\
\hline Sepsis & $9.59(4.69-19.60)$ & $<0.001$ & $6.06(3.68-10.0)$ & $<0.001$ \\
\hline Pneumonia & $1.67(0.67-4.14)$ & 0.2681 & $2.34(1.41-3.89)$ & 0.001 \\
\hline Stroke & $3.53(0.99-12.60)$ & 0.053 & $4.66(2.13-10.2)$ & $<0.001$ \\
\hline Urgency or emergency surgery & $3.21(1.81-5.69)$ & $<0.001$ & $1.47(1.1-1.97)$ & 0.010 \\
\hline \multicolumn{5}{|l|}{ MACE } \\
\hline Age, per year & $1.02(0.99-1.04)$ & 0.194 & $1.03(1.01-1.05)$ & 0.003 \\
\hline \multicolumn{5}{|l|}{ PMI } \\
\hline $\mathrm{PMI}_{\text {Infarct }}$ & $3.19(1.78-5.73)$ & $<0.001$ & $3.15(2.02-4.92)$ & $<0.001$ \\
\hline $\mathrm{PMI}_{\text {Injury }}$ & $2.22(1.32-3.77)$ & 0.003 & $1.67(1.09-2.54)$ & 0.018 \\
\hline RCRI score $\geq$ II & $3.30(2.23-4.89)$ & $<0.001$ & $2.98(2.24-3.95)$ & $<0.001$ \\
\hline Sepsis & $5.53(2.97-10.31)$ & $<0.001$ & $5.41(3.15-9.30)$ & $<0.001$ \\
\hline Pneumonia & $3.27(1.79-5.98)$ & $<0.001$ & $3.22(1.97-5.28)$ & $<0.001$ \\
\hline Stroke & $4.35(1.69-11.21)$ & 0.002 & $3.60(1.54-8.38)$ & 0.003 \\
\hline Urgent or emergency surgery & $1.95(1.31-2.91)$ & 0.001 & $1.68(1.25-2.26)$ & $<0.001$ \\
\hline
\end{tabular}

MACE Major adverse cardiovascular events, RCRI Revised Cardiac Risk Index, PMI perioperative myocardial infarction and injury, $C I$ confidence interval

\begin{tabular}{|c|c|c|c|c|}
\hline & $\begin{array}{l}\text { Adjusted Hazard } \\
\text { Ratio }(95 \% \mathrm{CI}) \\
30 \text { days }\end{array}$ & $P$ value & $\begin{array}{l}\text { Adjusted Hazard } \\
\text { Ratio }(95 \% \mathrm{CI}) \\
1 \text { year }\end{array}$ & $P$ value \\
\hline \multicolumn{5}{|l|}{ Mortality } \\
\hline Age, per year & $1.04(0.99-1.08)$ & 0.074 & $1.05(1.03-1.07)$ & $<0.001$ \\
\hline $\begin{array}{l}\text { PMI } \\
\text { PMI }_{\text {Infarct }} \\
\text { PMI }_{\text {Injury }}\end{array}$ & $\begin{array}{l}2.32(0.96-5.61) \\
2.53(1.30-4.91)\end{array}$ & $\begin{array}{l}0.061 \\
0.006\end{array}$ & $\begin{array}{l}1.66(1.02-2.71) \\
1.34(0.91-1.96)\end{array}$ & 0.135 \\
\hline RCRI Score $\geq$ II & $3.76(2.11-6.68)$ & $<0.001$ & $2.22(1.67-2.96)$ & $<0.001$ \\
\hline Sepsis & $9.30(4.47-19.37)$ & $<0.001$ & $5.99(3.60-9.97)$ & $<0.001$ \\
\hline Pneumonia & $1.38(0.53-3.62)$ & 0.513 & $2.37(1.41-3.99)$ & 0.001 \\
\hline Stroke & $3.80(1.06-13.62)$ & 0.040 & $4.92(2.24-10.80)$ & $<0.001$ \\
\hline Urgency or emergency surgery & $3.11(1.74-5.53)$ & $<0.001$ & $1.48(1.10-1.99)$ & 0.009 \\
\hline \multicolumn{5}{|l|}{ MACE } \\
\hline Age, per year & $1.02(0.99-1.04)$ & 0.194 & $1.03(1.01-1.05)$ & 0.003 \\
\hline \multicolumn{5}{|l|}{ PMI } \\
\hline $\mathrm{PMI}_{\text {Infarct }}$ & $3.91(2.26-6.77)$ & $<0.001$ & $3.12(2.03-4.79)$ & $<0.001$ \\
\hline $\mathrm{PMI}_{\text {Injury }}$ & $2.36(1.47-3.79)$ & $<0.001$ & $1.84(1.28-2.64)$ & 0.001 \\
\hline RCRI Score $\geq$ II & $3.18(2.15-4.72)$ & $<0.001$ & $2.95(2.23-3.92)$ & $<0.001$ \\
\hline Sepsis & $5.22(2.81-9.71)$ & $<0.001$ & $5.34(3.11-9.18)$ & $<0.001$ \\
\hline Pneumonia & $3.21(1.76-5.83)$ & $<0.001$ & $3.10(1.89-5.09)$ & $<0.001$ \\
\hline Stroke & $3.86(1.49-9.96)$ & 0.005 & $3.33(1.42-7.81)$ & 0.006 \\
\hline Urgent or emergency surgery & $2.00(1.34-2.98)$ & 0.001 & $1.69(1.26-2.27)$ & $<0.001$ \\
\hline
\end{tabular}

MACE Major adverse cardiovascular events, RCRI Revised Cardiac Risk Index, PMI perioperative myocardial infarction and injury, $C I$ confidence interval 


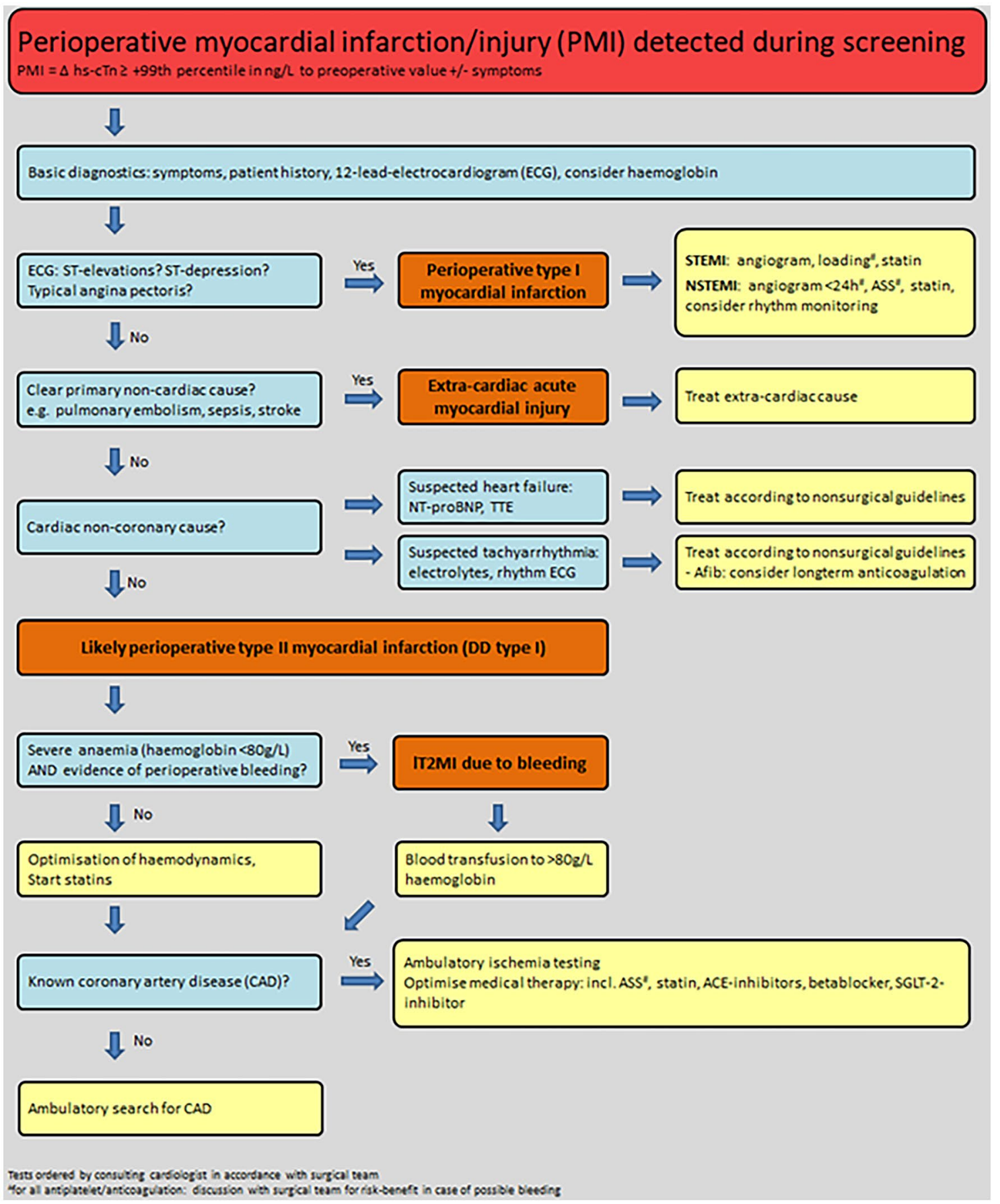

Fig. 3 Flowchart for the management of PMIPMI=perioperative myocardial infarction and injury; STEMI $=\mathrm{ST}$ elevation myocardial infarction; NSTEMI = non-ST elevation myocardial infarction;

or MINS in low-risk patients [37]. Second, our observations are based on the best validated and most widely used hs-cTnI assay. Further studies are necessary to evaluate to what extent our findings can be extrapolated to the recently developed novel hs-cTnI assays using other epitopes on the cTnI molecule $[38,39]$. Third, as with all observational/ afib = atrial fibrillation; TTE $=$ echocardiogram; IT2MI = initially type 2 myocardial infarction

diagnostic studies, the strong association between PMI/ MINS and the subsequent morbidity and mortality does not in itself prove causality. Fortunately, improved outcomes documented in the first randomized study targeting PMI/ MINS provide hope that early management measures will 
allow to at least mitigate the dismal outcome of patients with PMI/MINS [40].

\section{Conclusions}

Using hs-cTnI, PMI is less common versus using hs-cTnT, which was particularly associated with the non-biological equivalence of the approved URL of each assay. Using hscTnI, both PMIInfarct and PMIInjury remain independent predictors of all-cause mortality and MACE. The prognostic impact was comparable to PMIInfarct and PMIInjury diagnosed using hs-cTnT.

Supplementary Information The online version contains supplementary material available at https://doi.org/10.1007/s00392-021-01827-w.

Acknowledgement Other BASEL-PMI Investigators and contributors to this manuscript to be listed in Pubmed include:

Stella Marbot ${ }^{1}$, Ivo Strebel ${ }^{1}$, Alessandro Genini ${ }^{1}$, Katharina Rentsch $^{2}$, Jasper Boeddinghaus ${ }^{1}$, Thomas Nestelberger ${ }^{1}$, Karin Wildi $^{1}{ }^{3}$, Tobias Zimmermann, MD $^{1}{ }^{4}$, , Alberto J.S. Duarte ${ }^{6}$, Andreas Buser $^{7}$, Nelson de Luccia ${ }^{8}$, Luca Koechlin ${ }^{1}$, Desiree Wussler ${ }^{1}$, Joan Walter $^{1}$, Velina Widmer ${ }^{1}$, Michael Freese ${ }^{1}$, Pedro Lopez-Ayala ${ }^{1}$, Raphael Twerenbold ${ }^{1}$, Patrick Badertscher ${ }^{1}$, Esther Seeberger ${ }^{9}$, Thomas Wolff $^{11}$, Edin Mujagic ${ }^{10}$, Arne Mehrkens ${ }^{11}$ Julia Dinort $^{1}$, Gregor Fahrni $^{1}$, Raban Jeger ${ }^{1}$, Christoph Kaiser ${ }^{1}$, Mariana Matheus ${ }^{5}$, Adriana F. Pastana 5 .

${ }^{1}$ Department of Cardiology and Cardiovascular Research Institute Basel (CRIB), University Hospital Basel, University of Basel, Switzerland;

${ }^{2}$ Department of Laboratory Medicine, University Hospital Basel, Switzerland;

${ }^{3}$ Critical Care Research Group, The Prince Charles Hospital, Brisbane, Australia and The University of Queensland, Brisbane, Australia;

${ }^{4}$ Department of Internal Medicine, University Hospital Basel, University of Basel, Switzerland;

${ }^{5}$ Interdisciplinary Medicine in Cardiology Unit, Cardiology Department, Heart Institute (InCor), University of Sao Paulo Medical School, Brazil;

${ }^{6}$ Laboratory of Immunogenetics and Experimental Transplantation, University of Sao Paulo Medical School, Brazil;

${ }^{7}$ Blood bank and Department of Haematology, University Hospital Basel, Switzerland;

${ }^{8}$ Vascular and Endovascular Surgery Clinic of the Clinics Hospital, University of São Paulo Medical School, Brazil;

${ }^{9}$ Department of Anaesthesiology, University Hospital Basel, University of Basel, Switzerland;

${ }^{10}$ Department of Vascular Surgery, University Hospital Basel, University of Basel, Switzerland;

${ }^{11}$ Department of Spinal Surgery, University Hospital Basel, University of Basel, Switzerland.

Funding Open Access funding provided by Universität Basel (Universitätsbibliothek Basel). This work was supported by the Swiss National Science Foundation; the Swiss Heart Foundation; the University Hospital Basel; the University of Basel; the Cardiovascular Research Foundation Basel; Astra Zeneca; Abbott; Roche; the Clinical Research Program of the University of Basel; Spezialprogramm Nachwuchsförderung Klinische Forschung; Förderung Exzellenter Junger Forschender; Forschung fond Kantonsspital Aarau; Swiss Academy of Medical Sciences and the Bangerter Foundation; and Fundação de
Amparo à Pesquisa do Estado de São Paulo; Brazil [FAPESP Grant Number 2015/ 23731-6]. The funding source had no role in the study design, collection, analysis and interpretation of data or in the writing of the report.

Availability of data and material DG, CP und CM had access to all the data and take responsibility for the results.

\section{Declarations}

Conflict of interest Dr. Gualandro reports grants from FAPESP (Fundacao de Amparo a pesquisa do estado de Sao Paulo; Brasil); during the conduct of the study; personal fees from Roche; outside the submitted work; Dr. Puelacher reports grants from PhD Educational Platform for Health Sciences; grants from Roche Diagnostics; grants from University Hospital Basel; during the conduct of the study; other from Roche; outside the submitted work; Dr. Lurati Buse reports grants from University of Basel; during the conduct of the study; other from Roche Diagnostic; outside the submitted work; Dr. Cardozo reports personal fees from Bayer; outside the submitted work; Dr. Arslani reports grants from Swiss Academy of Medical Siences and the Bangerter Foundation; outside the submitted work; Dr. Calderaro reports personal fees from Bayer; personal fees from Janssen; personal fees from Daiichi Sankyo; from null; outside the submitted work; Dr. Hammerer-Lercher reports other from Roche Diagnostics; other from Abbott Diagnostics; other from Beckman Diagnostics; outside the submitted work; Dr. Kindler reports grants from Research Fund Kantonsspital Aarau; during the conduct of the study; Dr. Osswald reports grants from SNSF for Swiss-AF cohort study; outside the submitted work; Dr. Devereaux is a member of a research group with a policy of not accepting honorariums or other payments from industry for their own personal financial gain. They do accept honorariums/payments from industry to support research endeavours and costs to participate in meetings. Based on study questions he has originated and grants he has written; he has received grants from Abbott Diagnostics; AstraZeneca; Bayer; Boehringer Ingelheim; Bristol-Myers-Squibb; Coviden; Octapharma; Philips Healthcare; Roche Diagnostics and Stryker. Dr. Mueller has received research support/grants from the Swiss National Science Foundation, the Swiss Heart Foundation, the Cardiovascular Research Foundation Basel, the University Hospital Basel, the University of Basel, Abbott, Beckman Coulter, BRAHMS, Ortho Clinical, Quidel, Roche, Siemens, and Sphingotec, as well as speaker/consulting honoraria from Acon, Amgen, Astra Zeneca, Bayer, Boehringer Ingelheim, Osler, Novartis, Roche, and Sanofi. All other authors have no conflict of interest to declare.

Ethics approval and consent to participate The local ethics committees approved the protocol (NCT02573532/CAPPESQ 610608), and all patients provided written consent.

Open Access This article is licensed under a Creative Commons Attribution 4.0 International License, which permits use, sharing, adaptation, distribution and reproduction in any medium or format, as long as you give appropriate credit to the original author(s) and the source, provide a link to the Creative Commons licence, and indicate if changes were made. The images or other third party material in this article are included in the article's Creative Commons licence, unless indicated otherwise in a credit line to the material. If material is not included in the article's Creative Commons licence and your intended use is not permitted by statutory regulation or exceeds the permitted use, you will need to obtain permission directly from the copyright holder. To view a copy of this licence, visit http://creativecommons.org/licenses/by/4.0/. 


\section{References}

1. Weiser TG, Haynes AB, Molina G, Lipsitz SR, Esquivel MM, Uribe-Leitz T, Fu R, Azad T, Chao TE, Berry WR, Gawande AA (2015) Estimate of the global volume of surgery in 2012: an assessment supporting improved health outcomes. Lancet 385(Suppl 2):S11

2. Pearse RM, Moreno RP, Bauer P, Pelosi P, Metnitz P, Spies C, Vallet B, Vincent JL, Hoeft A, Rhodes A (2012) Mortality after surgery in Europe: a 7 day cohort study. Lancet 380(9847):1059-1065

3. Yu PC, Calderaro D, Gualandro DM, Marques AC, Pastana AF, Prandini JC, Caramelli B (2010) Non-cardiac surgery in developing countries: epidemiological aspects and economical opportunities-the case of Brazil. PLoS ONE 5(5):e10607

4. Puelacher C, Lurati Buse G, Seeberger D, Sazgary L, Marbot S, Lampart A, Espinola J, Kindler C, Hammerer A, Seeberger E, Strebel I, Wildi K, Twerenbold R, du Fay de Lavallaz J, Steiner L, Gurke L, Breidthardt T, Rentsch K, Buser A, Gualandro DM, Osswald S, Mueller C. (2018) Perioperative myocardial injury after noncardiac surgery: incidence, mortality, and characterization. Circulation 137(12):1221-1232

5. Devereaux PJ, Biccard BM, Sigamani A, Xavier D, Chan MTV, Srinathan SK, Walsh M, Abraham V, Pearse R, Wang CY, Sessler DI, Kurz A, Szczeklik W, Berwanger O, Villar JC, Malaga G, Garg AX, Chow CK, Ackland G, Patel A, Borges FK, Belley-Cote EP, Duceppe E, Spence J, Tandon V, Williams C, Sapsford RJ, Polanczyk CA, Tiboni M, Alonso-Coello P, Faruqui A, HeelsAnsdell D, Lamy A, Whitlock R, LeManach Y, Roshanov PS, McGillion M, Kavsak P, McQueen MJ, Thabane L, Rodseth RN, Buse GAL, Bhandari M, Garutti I, Jacka MJ, Schünemann HJ, Cortes OL, Coriat P, Dvirnik N, Botto F, Pettit S, Jaffe AS, Guyatt GH (2017) Association of postoperative high-sensitivity troponin levels with myocardial injury and 30-day mortality among patients undergoing noncardiac surgery. JAMA 317(16):1642-1651

6. Duceppe E, Parlow J, MacDonald P, Lyons K, McMullen M, Srinathan S, Graham M, Tandon V, Styles K, Bessissow A, Sessler DI, Bryson G, Devereaux PJ (2017) Canadian Cardiovascular Society Guidelines on perioperative cardiac risk assessment and management for patients who undergo noncardiac surgery. Can J Cardiol 33(1):17-32

7. Gualandro DM, Yu PC, Caramelli B, Marques AC, Calderaro D, Fornari LS, Pinho C, Feitosa ACR, Polanczyk CA, Rochitte CE, Jardim C, Vieira CLZ, Nakamura DYM, Iezzi D, Schreen D, Adam EL, D'Amico EA, Lima EQ, Burdmann EA, Mateo EIP, Braga FGM, Machado FS, Paula FJ, Carmo GALD, Feitosa-Filho GS, Prado GF, Lopes HF, Fernandes JRC, Lima JJG, Sacilotto L, Drager LF, Vacanti LJ, Rohde LEP, Prada LFL, Gowdak LHW, Vieira MLC, Monachini MC, Macatrão-Costa MF, Paixão MR, Oliveira MT, Cury P, Villaça PR, Farsky PS, Siciliano RF, Heinisch RH, Souza R, Gualandro SFM, Accorsi TAD, Mathias W (2017) 3rd Guideline for perioperative cardiovascular evaluation of the Brazilian Society of Cardiology. Arq Bras Cardiol 109(31):1-104

8. Mazzarello S, McIsaac DI, Montroy J, Fergusson DA, Yateem D, Devereaux PJ, Lalu MM (2019) Postoperative shared-care for patients undergoing non-cardiac surgery: a systematic review and meta-analysis. Can J Anaesth 66(9):1095-1105

9. Gualandro DM, Campos CA, Calderaro D, Yu PC, Marques AC, Pastana AF, Lemos PA, Caramelli B (2012) Coronary plaque rupture in patients with myocardial infarction after noncardiac surgery: frequent and dangerous. Atherosclerosis 222(1):191-195

10. Devereaux PJ, Chan MT, Alonso-Coello P, Walsh M, Berwanger O, Villar JC, Wang CY, Garutti RI, Jacka MJ, Sigamani A, Srinathan S, Biccard BM, Chow CK, Abraham V, Tiboni M, Pettit
S, Szczeklik W, Lurati Buse G, Botto F, Guyatt G, Heels-Ansdell D, Sessler DI, Thorlund K, Garg AX, Mrkobrada M, Thomas S, Rodseth RN, Pearse RM, Thabane L, McQueen MJ, VanHelder T, Bhandari M, Bosch J, Kurz A, Polanczyk C, Malaga G, Nagele P, Le Manach Y, Leuwer M, Yusuf S (2012) Association between postoperative troponin levels and 30-day mortality among patients undergoing noncardiac surgery. JAMA 307(24):2295-2304

11. Devereaux PJ, Szczeklik W (2019) Myocardial injury after noncardiac surgery: diagnosis and management. Eur Heart J. https:// doi.org/10.1093/eurheartj/ehz301

12. Thygesen K, Alpert JS, Jaffe AS, Chaitman BR, Bax JJ, Morrow DA, White HD (2019) Fourth universal definition of myocardial infarction. Eur Heart J 40:237-269

13. Klinkenberg LJ, Wildi K, van der Linden N, Kouw IW, Niens M, Twerenbold R, Rubini Gimenez M, Puelacher C, Daniel Neuhaus J, Hillinger P, Nestelberger T, Boeddinghaus J, Grimm K, Sabti Z, Bons JA, van Suijlen JD, Tan FE, Ten Kate J, Bekers O, van Loon LJ, van Dieijen-Visser MP, Mueller C, Meex SJ (2016) Diurnal rhythm of cardiac troponin: consequences for the diagnosis of acute myocardial infarction. Clin Chem 62(12):1602-1611

14. Artunc F, Mueller C, Breidthardt T, Twerenbold R, Peter A, Thamer C, Weyrich P, Haering HU, Friedrich B (2012) Sensitive troponins-which suits better for hemodialysis patients? Associated factors and prediction of mortality. PLoS ONE 7(10):e47610

15. McLaurin MD, Apple FS, Voss EM, Herzog CA, Sharkey SW (1997) Cardiac troponin I, cardiac troponin T, and creatine kinase MB in dialysis patients without ischemic heart disease: evidence of cardiac troponin $\mathrm{T}$ expression in skeletal muscle. Clin Chem 43(6 Pt 1):976-982

16. Lee TH, Marcantonio ER, Mangione CM, Thomas EJ, Polanczyk CA, Cook EF, Sugarbaker DJ, Donaldson MC, Poss R, Ho KK, Ludwig LE, Pedan A, Goldman L (1999) Derivation and prospective validation of a simple index for prediction of cardiac risk of major noncardiac surgery. Circulation 100(10):1043-1049

17. Kristensen SD, Knuuti J, Saraste A, Anker S, Bøtker HE, Hert SD, Ford I, Gonzalez-Juanatey JR, Gorenek B, Heyndrickx GR, Hoeft A, Huber K, Iung B, Kjeldsen KP, Longrois D, Lüscher TF, Pierard L, Pocock S, Price S, Roffi M, Sirnes PA, Sousa-Uva M, Voudris V, Funck-Brentano C (2014) 2014 ESC/ESA Guidelines on non-cardiac surgery: cardiovascular assessment and management: The Joint Task Force on non-cardiac surgery: cardiovascular assessment and management of the European Society of Cardiology (ESC) and the European Society of Anaesthesiology (ESA). Eur Heart J 35(35):2383-2431

18. Gualandro DM, Puelacher C, LuratiBuse G, Lampart A, Strunz C, Cardozo FA, Yu PC, Jaffe AS, Barac S, Bock L, Badertscher P, du Fay de Lavallaz J, Marbot S, Sazgary L, Bolliger D, Rentsch K, Twerenbold R, Hammerer-Lercher A, Melo E, Calderaro D, Duarte AJ, de Luccia N, Caramelli B, Mueller C. (2018) Comparison of high-sensitivity cardiac troponin I and T for the prediction of cardiac complications after non-cardiac surgery. Am Heart J 203:67-73

19. Koerbin G, Tate J, Potter JM, Cavanaugh J, Glasgow N, Hickman PE (2012) Characterisation of a highly sensitive troponin I assay and its application to a cardio-healthy population. Clin Chem Lab Med 50(5):871-878

20. McCarthy CP, Raber I, Chapman AR, Sandoval J, Apple FS, Mills NL, Januzzi JL (2019) Myocardial injury in the era of high-sensitivity cardiac troponin assays: a practical approach for clinicians. JAMA Cardiol 4(10): 1034-1042

21. Giannitsis E, Mueller-Hennessen M, Zeller T, Schuebler A, Aurich M, Biener M, Vafaie M, Stoyanov KM, Ochs M, Riffel J, Mereles D, Blankenberg S, Katus HA (2020) Gender-specific reference values for high-sensitivity cardiac troponin $\mathrm{T}$ and I in well-phenotyped healthy individuals and validity of highsensitivity assay designation. Clin Biochem 78:18-24 
22. Wildi K, Gimenez MR, Twerenbold R, Reichlin T, Jaeger C, Heinzelmann A, Arnold C, Nelles B, Druey S, Haaf P, Hillinger P, Schaerli N, Kreutzinger P, Tanglay Y, Herrmann T, Weidmann ZM, Krivoshei L, Freese M, Stelzig C, Puelacher C, Rentsch K, Osswald S, Mueller C (2015) Misdiagnosis of myocardial infarction related to limitations of the current regulatory approach to define clinical decision values for cardiac troponin. Circulation 131(23):2032-2040

23. Botto F, Alonso-Coello P, Chan MT, Villar JC, Xavier D, Srinathan S, Vascular events In noncardiac Surgery patIents cOhort evaluatioN (VISION) Writing Group, on behalf of The Vascular events In noncardiac Surgery patIents cOhort evaluatioN (VISION) (2014) Myocardial injury after noncardiac surgery: a large, international, prospective cohort study establishing diagnostic criteria, characteristics, predictors, and 30-day outcomes. Anesthesiology 120(3):564-578

24. du Fay de Lavallaz J, Zehntner T, Puelacher C, Walter J, Strebel I, Rentsch K, Boeddinghaus J, Nestelberger T, Twerenbold R, Mueller C. (2018) Rhabdomyolysis: a noncardiac source of increased circulating concentrations of cardiac troponin $\mathrm{T}$ ? J Am Coll Cardiol 72(3):2936-2937

25. Mair J, Lindahl B, Müller C, Giannitsis E, Huber K, Möckel M, Plebani M, Thygesen K, Jaffe AS (2018) What to do when you question cardiac troponin values. Eur Heart J Acute Cardiovasc Care 7(6):577-586

26. Mair J, Lindahl B, Hammarsten O, Müller C, Giannitsis E, Huber K, Möckel M, Plebani M, Thygesen K, Jaffe AS (2018) How is cardiac troponin released from injured myocardium? Eur Heart J Acute Cardiovasc Care 7(6):553-560

27. Kimenai DM, Henry RM, van der Kallen CJ, Dagnelie PC, Schram MT, Stehouwer CD, van Suijlen JD, Niens M, Bekers O, Sep SJ, Schaper NC, van Dieijen-Visser MP, Meex SJ (2016) Direct comparison of clinical decision limits for cardiac troponin T and I. Heart 102(8):610-616

28. Schmid J, Liesinger L, Birner-Gruenberger R, Stojakovic T, Scharnagl H, Dieplinger B, Asslaber M, Radl R, Beer M, Polacin M, Mair J, Szolar D, Berghold A, Quasthoff S, Binder JS, Rainer pp. (2018) Elevated cardiac troponin $\mathrm{T}$ in patients with skeletal myopathies. J Am Coll Cardiol 71(14):1540-1549

29. Rubini Gimenez M, Twerenbold R, Reichlin T, Wildi K, Haaf P, Schaefer M, Zellweger C, Moehring B, Stallone F, Sou SM, Mueller M, Denhaerynck K, Mosimann T, Reiter M, Meller B, Freese M, Stelzig C, Klimmeck I, Voegele J, Hartmann B, Rentsch K, Osswald S, Mueller C (2014) Direct comparison of high-sensitivity-cardiac troponin I vs T for the early diagnosis of acute myocardial infarction. Eur Heart J 35(34):2303-2311

30. Redfern G, Rodseth RN, Biccard BM (2011) Outcomes in vascular surgical patients with isolated postoperative troponin leak: a metaanalysis. Anaesthesia 66(7):604-610

31. Park J, Yang K, Lee SH, Lee JH, Min JJ, Kwon JH, Oh AR, Yeo J, Kim J, Choi JH, Lee SC, Gwon HC, Kim K, Ahn J, Lee SM (2020) Comparison of acute and chronic myocardial injury in noncardiac surgical patients. PLoS ONE 15(7):e0234776
32. Nagele P, Brown F, Gage BF et al (2013) High-sensitivity cardiac troponin $\mathrm{T}$ in prediction and diagnosis of myocardial infarction and long-term mortality after noncardiac surgery. Am Heart J 166(2):325-32.e1

33. Gillmann HJ, Meinders A, Grohennig A, Larmann J, Bünte C, Calmer S, Sahlmann B, Rustum S, Aper T, Lichtinghagen R, Koch A, Teebken OE, Theilmeier G (2014) Perioperative levels and changes of high-sensitivity troponin $\mathrm{T}$ are associated with cardiovascular events in vascular surgery patients. Crit Care Med 42(6):1498-1506

34. van Waes JA, Grobben RB, Nathoe HM, Kemperman H, de Borst GJ, Peelen LM, van Klei WA (2016) One-year mortality, causes of death, and cardiac interventions in patients with postoperative myocardial injury. Anesth Analg 123(1):29-37

35. Puelacher C, Gualandro DM, Lurati Buse G, Bolliger D, Marbot S, Kindler C, Hammerer-Lercher A, Gürke L, Steiner L, Mueller C (2020) Etiology of peri-operative myocardial infarction/injury after noncardiac surgery and associated outcome. J Am Coll Cardiol 76(16):1910-1912

36. Weber M, Luchner A, Manfred S, Mueller C, Liebetrau C, Schlitt A, Apostolovic S, Jankovic R, Bankovic D, Jovic M, Mitrovic V, Nef H, Mollmann H, Hammet CW (2013) Incremental value of high-sensitive troponin $\mathrm{T}$ in addition to the revised cardiac index for peri-operative risk stratification in non-cardiac surgery. Eur Heart J 34(11):853-862

37. Gualandro DM, Twerenbold R, Boeddinghaus J, Nestelberger T, Puelacher C, Mueller C (2019) Biomarkers in cardiovascular medicine: towards precision medicine. Swiss Med Wkly 149:w20125

38. Boeddinghaus J, Twerenbold R, Nestelberger T, Badertscher P, Wildi K, Puelacher C, du Fay de Lavallaz J, Keser E, Rubini Giménez M, Wussler D, Kozhuharov N, Rentsch K, Miró Ò, Martin-Sanchez FJ, Morawiec B, Stefanelli S, Geigy N, Keller DI, Reichlin T, Mueller C. (2018) Clinical validation of a novel high-sensitivity cardiac troponin I assay for early diagnosis of acute myocardial infarction. Clin Chem 64(9):1347-1360

39. Boeddinghaus J, Nestelberger T, Twerenbold R, Koechlin L, Meier M, Troester V, Wussler D, Badertscher P, Wildi K, Puelacher C, du Fay de Lavallaz J, Rubini Giménez M, Zimmermann T, Hafner B, Potlukova E, Miró Ò, Martin-Sanchez FJ, Keller DI, Reichlin T, Mueller C. (2019) High-sensitivity cardiac troponin I assay for early diagnosis of acute myocardial infarction. Clin Chem 65(7):893-904

40. Devereaux PJ, Duceppe E, Guyatt G, Tandon V, Rodseth R, Biccard BM, Xavier D, Szczeklik W, Meyhoff CS, Vincent J, Franzosi MG, Srinathan SK, Erb J, Magloire P, Neary J, Rao M, Rahate PV, Chaudhry NK, Mayosi B, de Nadal M, Iglesias PP, Berwanger O, Villar JC, Botto F, Eikelboom JW, Sessler DI, Kearon C, Pettit S, Sharma M, Connolly SJ, Bangdiwala SI, Rao-Melacini P, Hoeft A, Yusuf S (2018) Dabigatran in patients with myocardial injury after non-cardiac surgery (MANAGE): an international, randomised, placebo-controlled trial. Lancet 391(10137):2325-2334 